\title{
Age-Distinct Predictors of Symptomatic Cervicocephalic Atherosclerosis
}

\author{
Oh Young Bang ${ }^{a, d}$ Jeffrey L. Saver ${ }^{d}$ David S. Liebeskind ${ }^{d}$ Phil Hyu Lee $^{b}$ \\ Seung Soo Sheen ${ }^{c}$ Sa Rah Yoon ${ }^{e}$ Susan W. Yun ${ }^{d}$ Gyeong Moon Kim ${ }^{a}$ \\ Chin Sang Chung ${ }^{a}$ Kwang Ho Lee $^{a}$ Bruce Ovbiagele ${ }^{d}$ \\ a Department of Neurology, Samsung Medical Center, Sungkyunkwan University, and Departments of \\ ${ }^{b}$ Neurology and ${ }^{C}$ Clinical Epidemiology and Biostatistics, Ajou University, Seoul, South Korea; Departments of

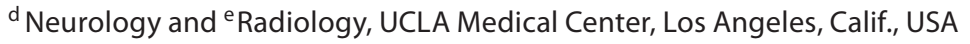

\section{Key Words}

Atherosclerosis · Vascular risk factors $\cdot$ Stenosis $\cdot$ Stroke $\cdot$

Ischemic stroke

\begin{abstract}
Background: Little is known about whether vascular risk factors predispose to atherosclerotic stroke depending on age. We evaluated predictors of large vessel atherosclerotic stroke (LVAS) stratified by age in two geographically and racially distinct study populations. Methods: Data collected over a 4-year period in prospectively maintained registries on 3,053 subjects with ischemic cerebrovascular events were analyzed: 1,982 patients from a hospital in South Korea and 1,071 patients admitted to a hospital in Los Angeles, Calif., USA. Independent vascular risk factor associations with LVAS mechanism were evaluated in three groups stratified by age (years) at symptom onset: young ( $\leq 50$ years), older (51-75 years), and oldest ( $>75$ years). Results: Altogether at both study sites, $972(31.8 \%)$ patients had LVAS mechanism, of whom 391 (40.2\%) were female. Risk factor profiles were not significantly different between LVAS versus other stroke mechanisms. Among young patients, after adjusting for covariates, current smoking was the only predictor of atherosclerotic stroke at both Korean (OR 2.04; 95\% Cl: 1.13-3.69) and Californian sites (OR 4.78, 95\% Cl 1.54-14.89), while the
\end{abstract}

metabolic syndrome was the only predictor of atherosclerotic stroke among the older patients (OR 1.58, 95\% Cl 1.172.12 for Korean; OR 1.75, 95\% Cl 1.07-2.84 for Californian), but not in the young or oldest groups. Conclusions: Across race and region, the estimated impact of vascular risk factors for LVAS varies by age, and this is most prominently seen among persons of less than 76 years of age. Some risk factors have an early effect (smoking) and others an effect that plays out over time.

Copyright $\odot 2008$ S. Karger AG, Basel

\section{Introduction}

Atherosclerosis is a major cause of first ischemic stroke $[1,2]$. Furthermore, the strongest predictor of early stroke recurrence is prior evidence of large artery atherosclerosis with $>50 \%$ arterial stenosis [3]. Both of these observations underscore the need to promptly and optimally institute prevention strategies in individuals with or at risk of aortocervicocephalic atherosclerosis. Great strides have been made in the identification of biological and lifestyle risk factors associated with atherosclerotic cerebrovascular disease $[4,5]$. However, the assessment of distinctions in predictors of symptomatic cerebrovascular atherosclerosis by age has been little studied, and

\section{KARGER}

Fax +41613061234 E-Mail karger@karger.ch www.karger.com
Oh Young Bang, MD, PhD

Department of Neurology, The Stroke and Cerebrovascular Center

Samsung Medical Center, Sungkyunkwan University, School of Medicine

50 Irwon-dong, Gangnam-gu, Seoul, 135-710 (South Korea)

Tel. +82 234103599 , Fax +82 23410 0052, E-Mail nmboy@unitel.co.kr 
could provide further insights into the underlying atherothrombotic disease process and focus risk factor modification on an individual and public health level, especially if consistent across race and ethnicity.

The objective of this study was to evaluate predictors of well-defined large vessel atherosclerotic stroke (LVAS) in persons of different ages. To test the robustness of any potential findings we sought to study two geographically and racially distinct study populations.

\section{Methods}

\section{Patients and Workups}

We analyzed data in prospectively maintained registries of patients admitted with ischemic stroke/TIA within 7 days after symptom onset from September 2002 through December 2006. Two different study populations were included in this analysis: 1,982 patients admitted to a university medical center in South Korea and 1,071 patients admitted to a university hospital stroke program in Los Angeles, Calif., USA [Non-Hispanic Whites 773 (72.2\%), African-Americans 96 (9.0\%), Asian-Americans 95 (8.9\%), and Hispanics 99 (9.2\%)].

Data in both Korean and Californian patients were collected according to the respective hospital protocols [6-8]. All the patients underwent comprehensive workups including routine blood tests, neuroimaging, vascular imaging and cardiac studies. Cervical and intracranial vessel imaging was generally obtained with MR angiography; CT angiography was performed if MRI was contraindicated. Select patients additionally underwent digital subtraction angiography at the physician's discretion. Electrocardiography was performed in all the patients and transthoracic echocardiography and/or Holter monitoring were performed in most patients, especially if the patient had one of the following characteristics: past vascular events such as stroke, coronary arterial occlusive disease (CAOD), or history, physical examination or EKG evidence of ventricular disease, palpitation preceding or accompanying stroke onset, or peripheral vascular insufficiency, deep vein thrombosis, or pulmonary embolism. Transesophageal echocardiography was performed in nonlacunar patients after an inconclusive initial diagnostic evaluation. For both study cohorts, in patients younger than 50 years, hemostatic markers of prothrombotic tendency were checked, including protein $\mathrm{C}$ and $\mathrm{S}$ levels, antiphospholipid antibodies (lupus anticoagulant and anticardiolipin antibody) and, in Californian patients, factor V Leiden and $\beta_{2}$-glycoprotein-1 antibody.

\section{Conventional and Novel Risk Factors for Atherosclerosis}

Sociodemographic, self-reported medical history and vascular risk biomarker data were assessed in both databases. CAOD was defined as history of coronary artery disease, physician-diagnosed myocardial infarct or angina pectoris, or EKG evidence of an old myocardial infarct prior to index stroke/TIA. Patients were divided into nonsmokers, ex-smokers, and current smokers depending on their smoking history at the time of symptom onset.

To define the metabolic syndrome, we used the Adult Treatment Panel III guidelines [9] with some modifications. For Korean patients, obesity was defined as waist circumferences of $\geq 90$ $\mathrm{cm}$ for men and $\geq 80 \mathrm{~cm}$ for women, using the revised Asia-Pacific criteria suggested by the World Health Organization. For Californian patients, instead of the waist circumference category, we used the body mass index $\geq 30 \mathrm{~kg} / \mathrm{m}^{2}$, which is the index of obesity used in the World Health Organization metabolic syndrome definition [10].

\section{Patient Grouping}

Based on their clinical syndromes, brain imaging (including diffusion-weighted imaging unless contraindicated), and the results of vascular and cardiologic studies, we divided the patients into two groups: LVAS versus other [8]. The 'other' group included cardioembolism, small arterial occlusion, other cause, and unknown (no determined cause, cause $>1$, and incomplete workups) [8]. Patients in the LVAS group were further subdivided according to their vascular status: (1) those with symptomatically relevant occlusive lesions ( $>50 \%$ stenosis or occlusion) of the extracranial portion of carotid or vertebral artery (extracranial atherosclerosis), and (2) those with symptomatically relevant occlusive lesions of the intracranial portion of internal carotid artery or the proximal portion of the middle cerebral artery (intracranial atherosclerosis). Patients were also classified in the intracranial atherosclerosis category if they had symptomatically relevant stenosis of the M2 middle cerebral artery branch or proximal segment of anterior $(\mathrm{A} 1)$ or posterior $(\mathrm{P} 1)$ cerebral artery with coexisting stenoses of symptomatically nonrelevant large intracranial vessels (intracranial portion of internal carotid artery or vertebral artery, basilar artery, or M1). Isolated stenosis on the M2, A1 or P1 segment was classified as cryptogenic cause (cryptogenic embolism).

The degree of stenosis was measured according to the NASCET method for extracranial lesions and the WASID method for intracranial lesions $[11,12]$. Patients with both extracranial and intracranial atherosclerosis were classified as having extracranial atherosclerosis.

\section{Statistical Analysis}

Stroke risk factors were evaluated in three age groups, stratified by the age at symptom onset: young ( $\leq 50$ years old), older (51-75 years old), and oldest ( $>75$ years old), to best reflect the age distributions across both cohorts (online suppl. fig. 1; for online supplemental material see www.karger.com/doi/172629). Statistical computations were performed separately in Korean and Californian patients. All risk factors were entered into a stepwise logistic regression model with LVAS as the dependent variable and potential risk factors as independent variables. Potential factors considered for inclusion in the model were (1) age, hypertension, diabetes, dyslipidemia, smoking habits (nonsmoker vs. ex-smoker vs. current smoker), metabolic syndrome, previous stroke/TIA, and CAOD and (2) laboratory findings including fasting serum levels of glucose, total cholesterol, and low-density lipoprotein cholesterol. In the analysis of the Californian patients, race and ethnicity (non-Hispanic Whites vs. African-Americans vs. Asian-Americans vs. Hispanics) were also included in multivariable testing, since racial and ethnic differences in stroke subtypes have previously been reported [13]. For each study cohort, two multivariable logistic regression models were used to determine the independent predictors for LVAS: (1) a multivariable logistic regression model controlling for age, sex and vascular risk factors was applied to determine the overall independent predictors of LVAS across the age groups ('age-adjusted' analysis) and (2) a mul- 
Table 1. Baseline characteristics of the two cohorts

\begin{tabular}{|c|c|c|c|}
\hline & $\begin{array}{l}\text { South Korean } \\
(\mathrm{n}=1,982)\end{array}$ & $\begin{array}{l}\text { Southern Californian } \\
(\mathrm{n}=1,071)\end{array}$ & $\mathrm{p}$ \\
\hline Male sex & $1,170(59.0 \%)$ & $567(52.9 \%)$ & 0.001 \\
\hline Age (mean $\pm S D)$, years & $62.3 \pm 12.9$ & $68.0 \pm 17.3$ & $<0.001$ \\
\hline$\leq 50$ & $369(18.6 \%)$ & $183(17.1 \%)$ & \\
\hline $51-75$ & $1,328(67.0 \%)$ & $445(41.6 \%)$ & \\
\hline$>75$ & $286(14.4 \%)$ & $443(41.3 \%)$ & \\
\hline \multicolumn{4}{|l|}{ Stroke subtypes } \\
\hline Atherosclerotic & $739(37.3 \%)$ & $233(21.8 \%)$ & $<0.001$ \\
\hline Intracranial & $496(25.0 \%)$ & $132(12.3 \%)$ & $<0.001$ \\
\hline Extracranial & $243(12.3 \%)$ & $101(9.4 \%)$ & $<0.001$ \\
\hline Cardioembolic & $325(16.4 \%)$ & $416(38.8 \%)$ & $<0.001$ \\
\hline Lacunar & $451(22.8 \%)$ & $190(17.7 \%)$ & 0.001 \\
\hline Other & $112(5.6 \%)$ & $111(10.4 \%)$ & $<0.001$ \\
\hline Undetermined & $355(17.9 \%)$ & $121(11.3 \%)$ & $<0.001$ \\
\hline TIA vs. stroke & $234(11.8 \%)$ & $151(14.1 \%)$ & 0.068 \\
\hline Vascular territory & & & 0.004 \\
\hline Carotid & $1,218(61.5 \%)$ & $729(68.1 \%)$ & \\
\hline Vertebrobasilar & $625(31.5 \%)$ & $280(26.1 \%)$ & \\
\hline Both & $45(2.3 \%)$ & $19(1.8 \%)$ & \\
\hline Unknown & $94(4.7 \%)$ & $43(4.0 \%)$ & \\
\hline \multicolumn{4}{|l|}{ Risk factors } \\
\hline Hypertension $^{1}$ & $1,179(59.5 \%)$ & $723(67.5 \%)$ & $<0.001$ \\
\hline Diabetes $^{1}$ & $559(28.2 \%)$ & $254(23.7 \%)$ & 0.009 \\
\hline Dyslipidemia $^{1}$ & $422(21.3 \%)$ & $384(35.9 \%)$ & $<0.001$ \\
\hline Smoking & & & $<0.001$ \\
\hline Ex-smoker & $156(7.9 \%)$ & $229(21.4 \%)$ & \\
\hline Current smoker & $670(33.8 \%)$ & $143(13.4 \%)$ & \\
\hline Metabolic syndrome & $627(42.9 \%)$ & $327(39.4 \%)$ & 0.101 \\
\hline Previous stroke/TIA & $467(23.6 \%)$ & $315(29.4 \%)$ & $<0.001$ \\
\hline CAOD & $180(9.1 \%)$ & $260(24.3 \%)$ & $<0.001$ \\
\hline
\end{tabular}

tivariable regression model to investigate whether independent predictors of LVAS differed significantly among the age groups ('age-distinct' analysis). Finally, regression analysis of a merged data set from both samples was performed to evaluate with greater power the impact of predictors independently associated with LVAS, although there were slight differences in hospital protocols and the collection of some variables differed between the two sites, e.g. waist circumference was collected in Korea and body mass index in California. Final significance was established at the $\mathrm{p}<0.05$ level.

\section{Results}

\section{Baseline Characteristics in the Two Cohorts}

As shown in table 1, the two samples differed significantly with regard to age, risk factors, and stroke sub- types (see also online suppl. fig. 1, 2). Korean patients were younger and more likely to have LVAS or lacunar stroke, whereas Californian patients were older and more likely to have cardioembolic sources or other causes of stroke. Among vascular risk factors, current smoking was more prevalent in Korea than California, whereas CAOD were more prevalent in the latter than in the former. Relatively few patients with unknown causes were found in both populations (online suppl. fig. 2).

LVAS was the presumed cause of stroke in 739 (37.3\%) Korean and 233 (21.8\%) Californian patients. The distribution of atherosclerosis was different depending on the study group: there was a higher prevalence of intracranial atherosclerosis in Korean compared to Californian patients (25.0 vs. $12.3 \%$ ). In both groups, age was an important determinant of the site of atherosclerosis. The ra- 
Table 2. Age, sex, risk factors, and laboratory findings in patients with large vessel atherosclerosis and other subtypes

\begin{tabular}{|c|c|c|c|c|c|c|c|c|}
\hline & \multicolumn{4}{|c|}{ South Korean } & \multicolumn{4}{|c|}{ Southern Californian } \\
\hline & $\begin{array}{l}\text { LVAS } \\
(\mathrm{n}=739)\end{array}$ & $\begin{array}{l}\text { other } \\
(\mathrm{n}=1,243)\end{array}$ & $\begin{array}{l}\text { crude } \\
\text { OR }\end{array}$ & $\begin{array}{l}\text { multivariate OR } \\
(95 \% \mathrm{CI})\end{array}$ & $\begin{array}{l}\text { LVAS } \\
(\mathrm{n}=233)\end{array}$ & $\begin{array}{l}\text { other } \\
(\mathrm{n}=838)\end{array}$ & $\begin{array}{l}\text { crude } \\
\text { OR }\end{array}$ & $\begin{array}{l}\text { multivariate OR } \\
(95 \% \mathrm{CI})\end{array}$ \\
\hline Female sex & $288(39 \%)$ & $525(42 \%)$ & 0.72 & $0.70(0.56-0.88)^{b}$ & $120(56 \%)$ & $437(52 \%)$ & 0.79 & \\
\hline Age, per 1-year increase & & & 1.01 & $1.01(1.00-1.02)^{\mathrm{a}}$ & & & 1.00 & \\
\hline$\leq 50$ & $107(15 \%)$ & $262(21 \%)$ & & & $32(14 \%)$ & $151(18 \%)$ & & \\
\hline $51-75$ & $534(72 \%)$ & $793(64 \%)$ & & & $121(52 \%)$ & $324(39 \%)$ & & \\
\hline$>75$ & $98(13 \%)$ & $188(15 \%)$ & & & $80(34 \%)$ & $363(43 \%)$ & & \\
\hline Hypertension & $473(64 \%)$ & $706(57 \%)$ & 1.18 & & $170(73 \%)$ & $553(66 \%)$ & 1.58 & $1.47(0.97-2.22)^{\mathrm{d}}$ \\
\hline Diabetes & $241(33 \%)$ & $318(26 \%)$ & 1.16 & & $64(28 \%)$ & $190(23 \%)$ & 0.83 & \\
\hline Dyslipidemia & $184(25 \%)$ & $238(19 \%)$ & 1.41 & $1.36(1.04-1.78)^{\mathrm{a}}$ & $108(47 \%)$ & $276(34 \%)$ & 1.42 & $1.37(0.95-1.97)^{\mathrm{d}}$ \\
\hline Current smoker & $250(34 \%)$ & $424(34 \%)$ & 1.13 & & $45(19 \%)$ & $98(12 \%)$ & 1.44 & \\
\hline Metabolic syndrome & $272(51 \%)$ & $355(38 \%)$ & 1.40 & $1.53(1.22-1.93)^{\mathrm{c}}$ & $94(51 \%)$ & $233(36 \%)$ & 1.48 & $1.41(0.98-2.03)^{\mathrm{d}}$ \\
\hline Previous stroke/TIA & $212(29 \%)$ & $255(21 \%)$ & 1.67 & $1.69(1.32-2.17)^{\mathrm{c}}$ & $79(34 \%)$ & $236(28 \%)$ & 1.42 & $1.36(0.95-1.96)^{\mathrm{d}}$ \\
\hline CAOD & $67(9 \%)$ & $113(9 \%)$ & 0.88 & & $52(22 \%)$ & $208(25 \%)$ & 0.84 & \\
\hline
\end{tabular}

${ }^{\mathrm{a}} \mathrm{p}<0.05 ;{ }^{\mathrm{b}} \mathrm{p}<0.01 ;{ }^{\mathrm{c}} \mathrm{p}<0.001 ;{ }^{\mathrm{d}} \mathrm{p}>0.05$

Table 3. Age-distinct risk factor profile: large vessel atherosclerosis vs. other subtypes

\begin{tabular}{|c|c|c|c|c|c|c|}
\hline & \multicolumn{3}{|c|}{ Large vessel atherosclerosis } & \multicolumn{3}{|c|}{ Other subtypes } \\
\hline & $\leq 50$ & $51-75$ & $>75$ & $\leq 50$ & $51-75$ & $>75$ \\
\hline South Korean & $\mathrm{n}=107$ & $\mathrm{n}=534$ & $\mathrm{n}=98$ & $\mathrm{n}=262$ & $\mathrm{n}=793$ & $\mathrm{n}=188$ \\
\hline Male sex & $82(76.6)^{*}$ & $318(59.6)$ & $51(52.0)$ & $194(74.0)^{*}$ & $447(56.4)$ & $77(41.0)$ \\
\hline Hypertension & $50(46.7)$ & $366(68.5)^{*}$ & $57(58.2)$ & $105(40.1)$ & $478(60.4)^{*}$ & $123(65.8)^{*}$ \\
\hline Diabetes & $21(19.6)$ & $205(38.4)^{*}$ & $15(15.3)$ & $32(12.2)$ & $242(30.6)^{*}$ & $44(23.5)$ \\
\hline Dyslipidemia & $21(19.6)$ & $153(28.7)$ & $10(10.2)$ & $51(19.7)$ & $160(20.3)$ & $27(14.4)$ \\
\hline Current smoker & $60(56.1)^{*}$ & $173(32.4)$ & $17(17.3)$ & $130(49.8)^{*}$ & $261(33.0)$ & $33(17.6)$ \\
\hline Metabolic syndrome & $24(33.3)$ & $227(57.8)^{*}$ & $21(30.9)$ & $50(27.0)$ & $237(40.9)^{*}$ & $68(41.7)^{*}$ \\
\hline Stroke/TIA & $24(22.4)$ & $160(30.0)$ & $28(28.6)$ & $48(18.4)$ & $173(21.9)$ & $34(18.1)$ \\
\hline CAOD & $4(3.7)$ & $51(9.6)$ & $12(12.2)$ & $19(7.3)$ & $77(9.7)$ & $17(9.0)$ \\
\hline Southern Californian & $\mathrm{n}=32$ & $\mathrm{n}=121$ & $\mathrm{n}=80$ & $\mathrm{n}=151$ & $\mathrm{n}=324$ & $\mathrm{n}=363$ \\
\hline Male sex & $19(59.4)$ & $69(57.0)$ & $42(52.5)$ & $68(45.0)$ & $192(59.3)^{*}$ & $177(48.8)$ \\
\hline Hypertension & $11(34.4)$ & $92(76.0)^{*}$ & $67(83.8)^{*}$ & $40(26.7)$ & $227(70.3)^{*}$ & $286(79.4)^{*}$ \\
\hline Diabetes & $5(15.6)$ & $45(37.2)^{*}$ & $14(17.5)$ & $14(9.3)$ & $99(30.7)^{*}$ & $77(21.4)^{*}$ \\
\hline Dyslipidemia & $11(35.5)$ & $64(53.8)$ & $33(41.3)$ & $27(18.5)$ & $117(37.0)^{*}$ & $132(38.5)^{*}$ \\
\hline Current smoker & $13(40.6)^{*}$ & $26(21.5)$ & $6(7.6)$ & $26(17.2)^{*}$ & $54(16.7)^{*}$ & $18(5.0)$ \\
\hline Metabolic syndrome & $10(43.5)$ & $60(62.5)^{*}$ & $24(35.8)$ & $38(32.5)$ & $114(45.1)^{*}$ & $81(29.7)$ \\
\hline Stroke/TIA & $8(25.0)$ & $40(33.1)$ & $31(38.8)^{*}$ & $27(18.0)$ & $89(27.6)$ & $120(33.3)^{*}$ \\
\hline CAOD & $2(6.3)$ & $24(19.8)$ & $26(32.5)^{*}$ & $3(2.0)$ & $74(22.9)$ & $131(36.4)^{*}$ \\
\hline
\end{tabular}

Figures in parentheses are percentages. ${ }^{*}$ Significant differences between the age groups.

tio of intracranial to extracranial disease was 3.9 for Korean and 3.6 for Californian patients of $\leq 50$ years of age, whereas it was 1.6 for Korean and 1.2 for Californian patients older than 75 years (online suppl. fig. 3; online suppl. table 1).
Age-Adjusted Multivariable Analysis of Vascular Risk Factors for Large Vessel Atherosclerosis

The frequencies of independent predictors in both study groups of LVAS and other subtypes regardless of age are shown in table 2 . The metabolic syndrome, previ- 


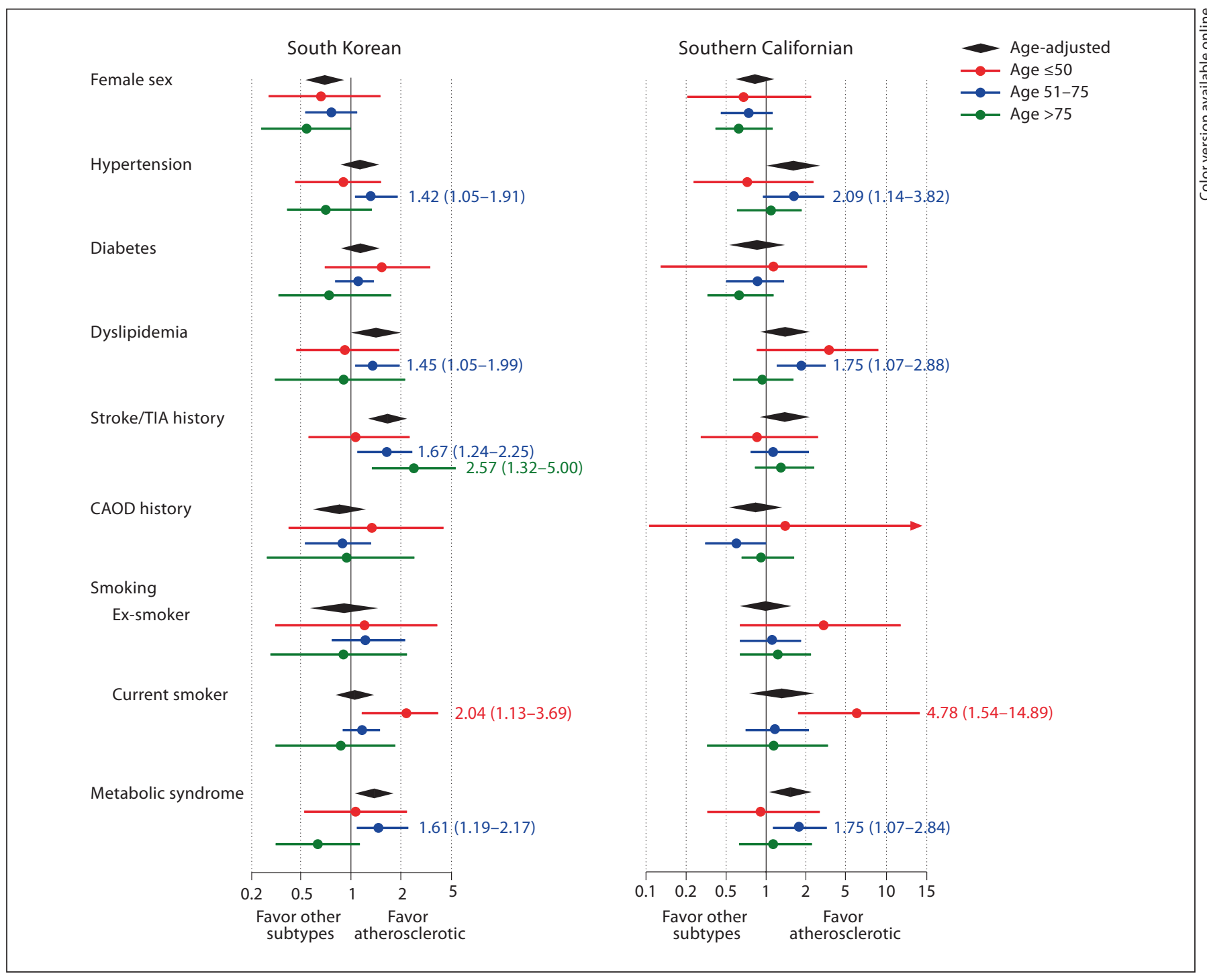

Fig. 1. OR of each risk factor for atherosclerosis. Results of univariate testing showed similar findings of agedistinct relationship between each risk factor and atherosclerotic stroke between two different populations. Values represent OR and 95\% CI results of multivariate testing ( $<<0.05$ in all the cases). Results of ethnicity and laboratory data are not shown in this funnel panel.

ous stroke or TIA, and dyslipidemia were associated with LVAS in both study cohorts; male sex and older age were independently associated with LVAS in Korean patients (table 2).

\section{Age-Distinct Multivariable Analysis of Vascular Risk}

Factors for Large Vessel Atherosclerosis

As shown in table 3, risk factor profiles and laboratory findings varied depending on the age of patients in both LVAS and other subtypes. Not surprisingly, across stroke subtypes, the prevalence of most vascular risk factors rose with increasing patient age. However, this observation did not apply to smoking habits and the presence of the metabolic syndrome. The highest prevalence of current smokers was observed in the young group (51.6\% for Koreans, $21.3 \%$ for Californians), and the lowest in the oldest group (17.5\% for Koreans, 5.5\% for Californians). In addition, the metabolic syndrome was most frequently observed in the older patients $(48.3 \%$ for Koreans, $49.9 \%$ for Californians) compared to the young and oldest groups (table 3; online suppl. table 1). 


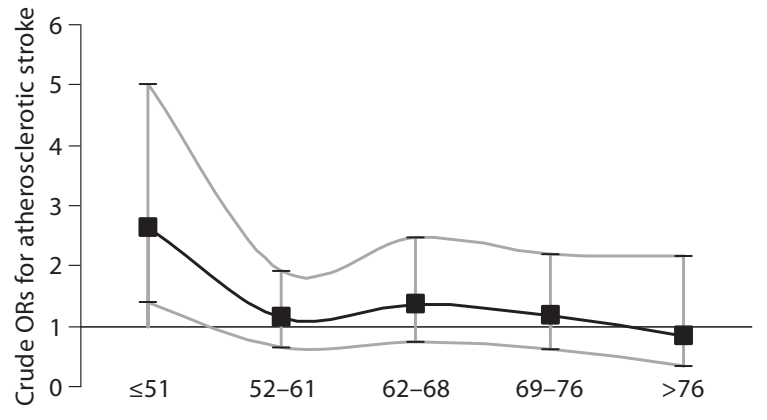

a

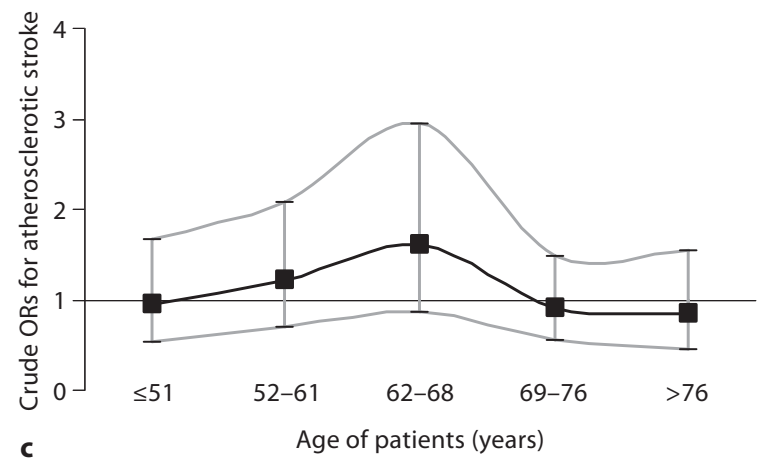

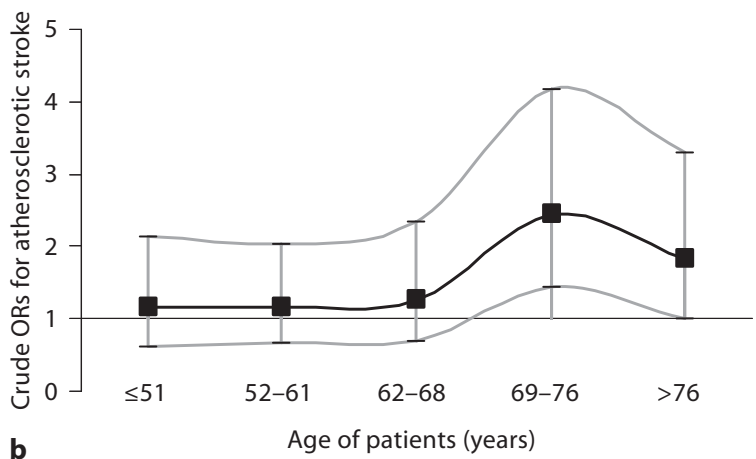

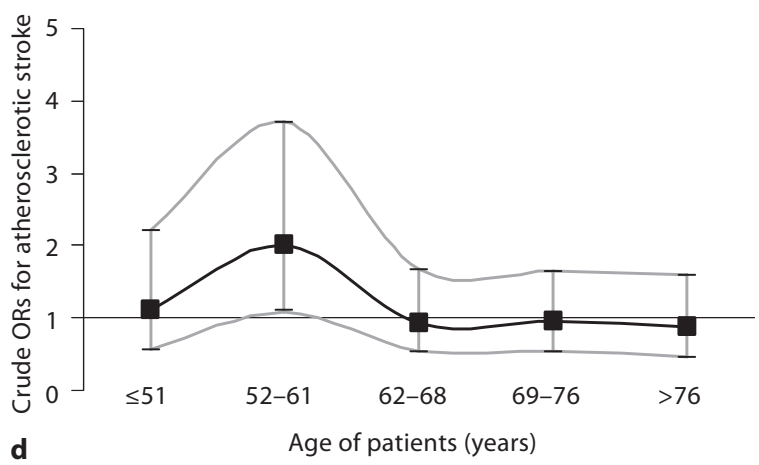

Fig. 2. Age-dependent changes in the risk of atherosclerotic stroke. The graphs demonstrate the observed relationship between LVAS and risk factors in five groups according to interquintile cutoff points of the distribution of age in the total study population: smoking habit (current smoking) (a), metabolic syndrome (b), hypertension (c), and dyslipidemia (d). Black line indicates crude OR and gray lines indicate 95\% CI.

Results of the age-distinct logistic regression analysis are shown in figure 1. Independent predictors for LVAS differed by age group. The odds ratios (OR) and 95\% confidence intervals (CI) of risk factors for LVAS were similar between Korean and Californian patients (fig. 1). Several risk factors that were not independent predictors in age-adjusted analysis were found to be independently associated with LVAS in age-distinct analysis. For both Korean $(\mathrm{p}=0.018)$ and Californian patients $(\mathrm{p}=0.007)$ of the young age group, current smoking was the only independent risk factor for LVAS. For patients of the older group, hypertension and dyslipidemia were independently associated with LVAS in both study cohorts. The presence of the metabolic syndrome was an independent predictor for LVAS in both the older Korean patients $(\mathrm{p}=0.003)$ and the older Californian patients $(\mathrm{p}=0.026)$, but not in the younger or oldest group of either study site. Lastly, previous stroke/TIA was the only significant predictor of LVAS in the oldest group among Korean patients, but there were no independent significant predictors of LVAS among the oldest Californian patients.

\section{Merged Dataset Analysis of Vascular Risk Factors for \\ Large Vessel Atherosclerosis}

Patients were stratified into five groups according to interquintile cutoff points of the distribution of age in the total study population. The results of univariate analysis of a merged data set (Korean and Californian) also showed age-adjusted changes in the impact of current smoking and metabolic syndrome (fig. 2). 
Table 4. Age-adjusted vascular risk factors for LVAS: population-based studies

\begin{tabular}{|c|c|c|c|c|c|}
\hline Country & Ethnicity & $\begin{array}{l}\text { Study period } \\
\text { year }\end{array}$ & $\begin{array}{l}\text { Atherosclerotic } \\
\text { subtype among } \\
\text { total strokes }\end{array}$ & $\begin{array}{l}\text { Age } \\
\text { range } \\
\text { years }\end{array}$ & Predictors for LVAS \\
\hline US-ARIC [20] & $\begin{array}{l}\text { Whites } 77 \% \\
\text { Blacks 23\% }\end{array}$ & $1987-1989$ & 326 of 531 & $46-64$ & $\begin{array}{l}\text { Hypertension, diabetes, current smoking, } \\
\text { central obesity, previous coronary heart } \\
\text { disease, elevated levels of lipoprotein, von } \\
\text { Willebrand factor, and white blood cells }{ }^{1}\end{array}$ \\
\hline US-Rochester [21] & $\begin{array}{l}\text { Whites } 96 \% \\
\text { Non-Whites 4\% }\end{array}$ & $1985-1989$ & 74 of 454 & All & Male sex and cigarette smoking ${ }^{2}$ \\
\hline US-GCNKSS [22] & $\begin{array}{l}\text { Whites } 81 \% \\
\text { Blacks } 19 \%\end{array}$ & 1993-1994 & 231 of 1,956 & All & $\begin{array}{l}\text { Blacks, current smoking, and previous } \\
\text { TIA }^{2}\end{array}$ \\
\hline $\begin{array}{l}\text { England-OCSP and } \\
\text { OXVASC [19] }\end{array}$ & Whites & $\begin{array}{l}1981-1986 \text { in OCSP } \\
2002 \text { in OXVASC }\end{array}$ & 94 of 647 & All & $\begin{array}{l}\text { Male sex, previous TIA, } \\
\text { hypercholesterolemia }^{2}\end{array}$ \\
\hline Germany-ESPro [23] & Whites & 1994-1998 & 71 of 583 & All & Cigarette smoking $^{2}$ \\
\hline US-GCNKSS [24] & Blacks & 1993 & 12 of 181 & All & Younger $(<65$ year $)$ age $^{2}$ \\
\hline Japan-Hisayama [25] & Asians & $1961-1993$ & 29 of 144 & $\geq 40$ & $\begin{array}{l}\text { Age and systolic blood pressure in both } \\
\text { men and women, and ST depression on } \\
\text { electrocardiogram in women }{ }^{1}\end{array}$ \\
\hline Chile-PISCIS [26] & $\begin{array}{l}\text { Hispanic and } \\
\text { Mestizo }\end{array}$ & $2000-2002$ & 8 of 185 & All & No significant factor ${ }^{2}$ \\
\hline US-NOMASS [27] & $\begin{array}{l}\text { Hispanics } 46 \% \\
\text { Blacks } 35 \% \\
\text { Whites } 19 \%\end{array}$ & $1990-1993$ & 73 of 438 & $\geq 40$ & $\begin{array}{l}\text { Non-Whites, younger age, history of } \\
\text { hypercholesterolemia, insulin-dependent } \\
\text { diabetes }^{2,3}\end{array}$ \\
\hline
\end{tabular}

ARIC = Atherosclerosis Risk in Communities study; GCNKSS = Greater Cincinnati/Northern Kentucky Stroke Study; OCSP = Oxfordshire Community Stroke Project; OXVASC = Oxford Vascular study; ESPro = Erlangen Stroke Project; PISCIS = Proyecto Investigacion de Stroke en Chile-Iquique Stroke study; NOMASS = Northern Manhattan Stroke Study.

${ }^{1}$ Compared to controls.

${ }^{2}$ Compared to other subtypes.

${ }^{3}$ Only for intracranial atherosclerotic stroke.

\section{Discussion}

In this study of stroke and TIA patients in two geographically and racially distinct study populations, agedependent associations of risk factors with large vessel atherosclerotic mechanism were demonstrated. Remarkably yet reassuringly, the results were rather similar in both study groups and strongly suggested that lifestyle practices may play a prominent role in predicting symptomatic large vessel atherosclerotic disease in patients at or under the age of 75 years. Among those patients, the estimated impact of vascular risk factors for LVAS varies by age. The possible explanation for this is that some risk factors have an early effect (smoking) and others an effect that plays out over time; some risk factors may have rap- id or direct effects on vascularity, whereas other effects do not emerge until later in life and, therefore, are less relevant to younger persons.

First, at both sites among patients $\leq 50$, we found smoking to be the only independent predictor of LVAS. Smoking is of course a well-known stroke risk factor [4, 14], but our study indicates that it may be preeminent in predicting LVAS in younger adults, which accords with other studies that have identified smoking as the major risk factor for overall stroke in early middle age $[15,16]$. Our data further reinforce the need to start smoking cessation counseling at a young age, but continue it at all ages.

Among patients at the age of 51-75 years at both sites, in addition to a history of hypertension and dyslipidemia, 
the presence of the metabolic syndrome also independently predicted LVAS. Although the metabolic syndrome criteria themselves include blood pressure and lipid components [9], this result underscores the potential impact of lifestyle modification (promoted via therapeutic lifestyle counseling) [9], particularly weight loss, on reducing the LVAS risk amongst individuals in their 50 s to 70 s. Among the oldest patients, we found that only a history of a prior cerebrovascular event predicted LVAS in the Korean patients, and observed no independent predictors in the elderly Californian patients. The paucity of established vascular risk factor predictors among the elderly in both cohorts likely reflects the role of very mature age as a powerful predictor of stroke to the extent that its effects overwhelm independent contributions from other vascular risk factors. Although metaanalysis data found evidence that the metabolic syndrome is an important risk factor for stroke [17], a recent population-based study has shown that the metabolic syndrome was not associated with vascular disease in people aged 85 years or older, and suggested that this could be a survivor effect [18].

To the best of our knowledge, the age-dependent impact of modifiable risk factors on LVAS has not been comprehensively studied. Several prior studies have looked at predictors for LVAS, but a relatively small number of LVAS were included and results have often varied (table 4) [19-27]. Possible explanations for some of these inconsistencies could be racial, ethnic [28], or geographic differences, as well as a lack of detailed workups to determine stroke etiology. The changing risk factor profile for LVAS by increasing age noted in our study supports prior work that has shown that the vascular risk conferred by certain factors is influenced by age. For instance, among patients with atrial fibrillation, population-attributable risks of atrial fibrillation for stroke vary, increasing from $1.5 \%$ in subjects aged $50-60$ years to $23.5 \%$ for subjects aged $80-89$ years [14]. Similarly, population-attributable risks of hypertension vary significantly among age groups being $40 \%$ in 50 -year-olds, $30 \%$ in 70 -year-olds and almost nonexistent for 90 -year-olds [14, 29]. Also, the risk of stroke with current cigarette smoking decreases with increasing age [29], although this finding noted in our study and prior studies likely in part reflects a survival effect. Since smokers are susceptible to other life-threatening illnesses, the potential for smoking to contribute to LVAS in the older and oldest patients was likely attenuated, as the smokers died earlier on.

Several prior studies [19-27] have examined independent associations between LVAS and potential predictors, but were largely controlled for age among other confounders. In our study, we performed both age-adjusted and age-distinct analyses, and our results suggest that some age-specific vascular risk factors might lose their significance if an analysis of predictors of LVAS is simply done in an age-adjusted way. Our study has several other strengths. A fairly large number of patients were studied with extensive workups including the use of multimodal MRI, and the contribution of a novel vascular risk factor, the metabolic syndrome, was analyzed. Also, two racially and geographically distinct ischemic cerebrovascular disease populations were evaluated and showed similar multivariable results. Finally, comprehensive testing was conducted at each site in all patients, which improved the presumed diagnosis of LVAS and reduced the proportion of strokes of unknown causes. However, there are study limitations worthy of mention. Although we performed multivariable testing, unmeasured confounding (i.e., chronic obstructive pulmonary disease and serum levels of C-reactive protein $[30,31]$ ) could still affect our results. In addition, the control population was not included in this study. Thus, the results of this study should be interpreted with caution; our results in a cohort that includes only stroke patients cannot be generalized to a population without stroke. Further studies that include patients without stroke are needed.

In conclusion, we found that the estimated impact of vascular risk factors for LVAS varies by age, and this is most prominently seen among persons less than 76 years of age. Significance of risk factors evaluated for specific age groups, in addition to across all ages, should be reflected in further clinical research and preventive efforts against the burden of ischemic stroke. Just as there are age-distinct differences in independent predictors for LVAS, a differential impact of risk factors may also exist in cardioembolic and lacunar stroke and may merit further study. Given the preeminence of lifestyle-related predictors of LVAS among the nonelderly, behavioral modification remains a potent yet underused weapon in our arsenal for reducing stroke in young and older persons.

\section{Acknowledgment}

This study was supported by a grant of the Korean Healthcare Technology R\&D Project, Ministry of Health and Welfare, Republic of Korea (A080044). 


\section{References}

- 1 Thom T, Haase N, Rosamond W, Howard VJ, Rumsfeld J, Manolio T, Zheng ZJ, Flegal K, O'Donnell C, Kittner S, Lloyd-Jones D, Goff DC Jr, Hong Y, Adams R, Friday G, Furie K, Gorelick P, Kissela B, Marler J, Meigs J, Roger V, Sidney S, Sorlie P, Steinberger J, Wasserthiel-Smoller S, Wilson M, Wolf P: Heart disease and stroke statistics - 2006 update: a report from the American Heart Association Statistics Committee and Stroke Statistics Subcommittee. Circulation 2006;113:e85e151.

2 Warlow C, Dennis MS, Van Gijn J, Hankey GJ, Sandercock PA, Bamford J, Wardlaw J: What caused this ischaemic event?; in Stroke: a Practical Guide to Management. Oxford, Blackwell Science, 2001, pp 223-300.

3 Hankey GJ: Long-term outcome after ischaemic stroke/transient ischaemic attack. Cerebrovasc Dis 2003; 16(suppl 1):14-19.

-4 Sacco RL, Adams R, Albers G, Alberts MJ, Benavente O, Furie K, Goldstein LB, Gorelick P, Halperin J, Harbaugh R, Johnston SC, Katzan I, Kelly-Hayes M, Kenton EJ, Marks M, Schwamm LH, Tomsick T: Guidelines for prevention of stroke in patients with ischemic stroke or transient ischemic attack: a statement for healthcare professionals from the American Heart Association/American Stroke Association Council on Stroke: cosponsored by the Council on Cardiovascular Radiology and Intervention: the American Academy of Neurology affirms the value of this guideline. Stroke 2006;37:577-617.

5 Gorelick PB: Stroke prevention therapy beyond antithrombotics: unifying mechanisms in ischemic stroke pathogenesis and implications for therapy: an invited review. Stroke 2002;33:862-875.

-6 Bang OY, Lee PH, Joo SY, Lee JS, Joo IS, Huh $\mathrm{K}$ : Frequency and mechanisms of stroke recurrence after cryptogenic stroke. Ann Neurol 2003; 54:227-234.

7 Smaha LA: The American Heart Association Get With The Guidelines program. Am Heart J 2004;148:S46-S48.

-8 Lee LJ, Kidwell CS, Alger J, Starkman S, Saver JL: Impact on stroke subtype diagnosis of early diffusion-weighted magnetic resonance imaging and magnetic resonance angiography. Stroke 2000;31:1081-1089.

$\checkmark 9$ Third Report of the National Cholesterol Education Program (NCEP) Expert Panel on Detection, Evaluation, and Treatment of High Blood Cholesterol in Adults (Adult Treatment Panel III) final report. Circulation 2002;106:3143-3421.

10 Alberti KG, Zimmet PZ: Definition, diagnosis and classification of diabetes mellitus and its complications. 1. Diagnosis and classification of diabetes mellitus provisional report of a WHO consultation. Diabet Med 1998;15: 539-553.

Age-Distinct Predictors of

Atherosclerotic Stroke
11 Beneficial effect of carotid endarterectomy in symptomatic patients with high-grade carotid stenosis. North American Symptomatic Carotid Endarterectomy Trial Collaborators. N Engl J Med 1991;325:445-453.

12 Samuels OB, Joseph GJ, Lynn MJ, Smith HA, Chimowitz MI: A standardized method for measuring intracranial arterial stenosis. AJNR Am J Neuroradiol 2000;21:643-646.

13 White H, Boden-Albala B, Wang C, Elkind MS, Rundek T, Wright CB, Sacco RL: Ischemic stroke subtype incidence among whites, blacks, and Hispanics: the Northern Manhattan Study. Circulation 2005;111:1327-1331.

14 Goldstein LB, Adams R, Alberts MJ, Appel LJ, Brass LM, Bushnell CD, Culebras A, Degraba TJ, Gorelick PB, Guyton JR, Hart RG, Howard G, Kelly-Hayes M, Nixon JV, Sacco RL: Primary prevention of ischemic stroke: a guideline from the American Heart Association/American Stroke Association Stroke Council: cosponsored by the Atherosclerotic Peripheral Vascular Disease Interdisciplinary Working Group; Cardiovascular Nursing Council; Clinical Cardiology Council; Nutrition, Physical Activity, and Metabolism Council; and the Quality of Care and Outcomes Research Interdisciplinary Working Group: the American Academy of Neurology affirms the value of this guideline. Stroke 2006;37:1583-1633.

15 Lee TH, Hsu WC, Chen CJ, Chen ST: Etiologic study of young ischemic stroke in Taiwan. Stroke 2002;33:1950-1955.

-16 Johnson HM, Douglas PS, Srinivasan SR Bond MG, Tang R, Li S, Chen W, Berenson GS, Stein JH: Predictors of carotid intimamedia thickness progression in young adults: the Bogalusa Heart Study. Stroke 2007;38: 900-905.

-17 Li W, Ma D, Liu M, Liu H, Feng S, Hao Z, Wu B, Zhang S: Association between metabolic syndrome and risk of stroke: a meta-analysis of cohort studies. Cerebrovasc Dis 2008;25: 539-547.

18 van den Berg E, Biessels GJ, de Craen AJ, Gussekloo J, Westendorp RG: The metabolic syndrome is associated with decelerated cognitive decline in the oldest old. Neurology 2007;69:979-985

19 Schulz UG, Rothwell PM: Differences in vascular risk factors between etiological subtypes of ischemic stroke: importance of population-based studies. Stroke 2003;34: 2050-2059.

20 Ohira T, Shahar E, Chambless LE, Rosamond WD, Mosley TH Jr, Folsom AR: Risk factors for ischemic stroke subtypes: the Atherosclerosis Risk in Communities study. Stroke 2006;37:2493-2498.

21 Petty GW, Brown RD Jr, Whisnant JP, Sicks JD, O'Fallon WM, Wiebers DO: Ischemic stroke subtypes: a population-based study of incidence and risk factors. Stroke 1999;30: 2513-2516.
22 Schneider AT, Kissela B, Woo D, Kleindorfer D, Alwell K, Miller R, Szaflarski J, Gebel J, Khoury J, Shukla R, Moomaw C, Pancioli A, Jauch E, Broderick J: Ischemic stroke subtypes: a population-based study of incidence rates among blacks and whites. Stroke 2004; 35:1552-1556.

-23 Kolominsky-Rabas PL, Weber M, Gefeller O, Neundoerfer B, Heuschmann PU: Epidemiology of ischemic stroke subtypes according to TOAST criteria: incidence, recurrence, and long-term survival in ischemic stroke subtypes: a population-based study. Stroke 2001;32:2735-2740.

24 Woo D, Gebel J, Miller R, Kothari R, Brott T, Khoury J, Salisbury S, Shukla R, Pancioli A, Jauch E, Broderick J: Incidence rates of firstever ischemic stroke subtypes among blacks: a population-based study. Stroke 1999;30: 2517-2522.

25 Tanizaki Y, Kiyohara Y, Kato I, Iwamoto H, Nakayama K, Shinohara N, Arima H, Tanaka K, Ibayashi S, Fujishima M: Incidence and risk factors for subtypes of cerebral infarction in a general population: the Hisayama study. Stroke 2000;31:2616-2622.

-26 Lavados PM, Sacks C, Prina L, Escobar A, Tossi C, Araya F, Feuerhake W, Galvez M, Salinas R, Alvarez G: Incidence, case-fatality rate, and prognosis of ischaemic stroke subtypes in a predominantly Hispanic-Mestizo population in Iquique, Chile (PISCIS project): a community-based incidence study. Lancet Neurol 2007;6:140-148.

-27 Sacco RL, Kargman DE, Gu Q, Zamanillo MC: Race-ethnicity and determinants of intracranial atherosclerotic cerebral infarction. The Northern Manhattan Stroke Study. Stroke 1995;26:14-20.

-28 Sacco RL, Boden-Albala B, Abel G, Lin IF, Elkind M, Hauser WA, Paik MC, Shea S: Race-ethnic disparities in the impact of stroke risk factors: the northern Manhattan stroke study. Stroke 2001;32:1725-1731.

29 Whisnant JP, Wiebers DO, O'Fallon WM, Sicks JD, Frye RL: A population-based model of risk factors for ischemic stroke: Rochester, Minnesota. Neurology 1996;47:14201428

-30 Arboix A, Morcillo C, Garcia-Eroles L, Oliveres M, Massons J, Targa C: Different vascular risk factor profiles in ischemic stroke subtypes: a study from the 'Sagrat Cor Hospital of Barcelona Stroke Registry'. Acta Neurol Scand 2000;102:264-270.

- 31 Curb JD, Abbott RD, Rodriguez BL, Sakkinen P, Popper JS, Yano K, Tracy RP: C-reactive protein and the future risk of thromboembolic stroke in healthy men. Circulation 2003;107:2016-2020. 